\title{
ENSINO DE ENFERMAGEM PSIQUIÁTRICA / SAÚDE MENTAL NA FACULDADE DE ENFERMAGEM DA UNIVERSIDADE FEDERAL DE GOIÁS
}

\author{
Psychiatric Nursing and Mental Health Education in Nursing College \\ of the Federal University of Goiás - Brazil \\ Enseñanza de Enfermería Psiquiátrica $Y$ de Salud Mental en la \\ Facultad de Enfermería de la Universidad Federal de Goiás - Brasil
}

Denize Bouttelet Munari

Maria Tereza Hagen Godoy

Elizabeth Esperidião

\begin{abstract}
Resumo
Este artigo descreve a experiência do ensino em Enfermagem Psiquiátrica/Saúde Mental na Faculdade de Enfermagem/Universidade Federal de Goiás, pontuando potencialidades e fragilidades na busca de novos caminhos para atenção em enfermagem de saúde mental e psiquiatria. Destacamos aspectos relevantes como facilidade de integração entre as disciplinas da área com outras áreas, a contribuição na formação geral do enfermeiro no desenvolvimento de competências relacionais, de gestão, de capacitação para compreender, planejar e desenvolver ações de resgate da humanização nos serviços de saúde, com destaque especial ao cuidado do cuidador. Como fator limitante, pontuamos a fragilidade da rede de serviços de atenção psicossocial que constitui um obstáculo e grande desafio a ser superado para a implementação de mudanças na assistência e ensino.
\end{abstract}

Palavras-chave: Enfermagem Psiquiátrica.Saúde Mental. Educação em Enfermagem.

\begin{abstract}
This article describes the experience of education in Mental Health and Psychiatric Nursing in the Nursing College of Federal University of Goiás, marking potentialities and fragilities in the search for new ways of attention in mental health and psychiatry nursing. We detach some important aspects as easy integration among the disciplines of different areas, the contribution to the nurses' general formation in the development of related abilities, management and qualification to understand, to plan and to develop actions that will rescue the humanistic assistance at the health services, with special attention to take care of who take care. The limiting factor found was the fragility of the psychosocial care attention services that constitutes an obstacle and a challenge to be exceed for the implementation of changes in the assistance and education.
\end{abstract}

Keywords:

Psychiatric Nursing. Mental Health. Nursing Education.

\section{Resumen}

Este artículo describe la experiencia de enseñanza en Enfermería Psiquiátrica/Salud Mental en la Escuela de Enfermería de la Universidad Federal de Goiás puntuando potencialidades y fragilidades en la búsqueda de nuevas maneras de atención en enfermería de salud mental y psiquiatría. Enfatizamos aspectos importantes como facilidad de integración entre varias disciplinas de áreas diferentes, la contribución en la formación general del enfermero en el desarrollo de habilidades de relacionar, la administración, de calificación para entender, planear y desarrollar acciones para rescatar ayuda humanística en servicios de salud, con destaque especial al cuidado de aquel que cuida. Como factor limitante puntuamos la fragilidad de la red de servicios de atención psicosocial que constituye un obstáculo y gran desafío de ser superados para la implementación de cambios en el cuidado y enseñanza.

Palabras clave: Enfermería Psiquiátrica. Salud Mental. Educación en Enfermería. 


\section{INTRODUÇÃO}

0 cuidado em psiquiatria vem desde há muito sendo um constante desafio para a humanidade por se constituir em um dos mistérios a ser desvendado na nossa história. De igual forma, a atenção nessa área, historicamente, é marcada pela busca incessante na definição do que pode ser considerado normal ou patológico, bem como de decifrar patologias, diagnósticos e buscar formas de tratar os possíveis desvios ${ }^{1-2}$.

A mesma trajetória histórica nos mostra que as pessoas acometidas por transtornos mentais tiveram por muitos e longos anos a internação psiquiátrica como única opção para seu tratamento por períodos de meses ou até anos. A constatação de que essa estratégia, na verdade, se constitui em uma prática perniciosa, excludente e desumana, aliada ao desenvolvimento de terapêuticas farmacológicas, psicoterápicas e sociais fizeram surgir um novo conceito de cuidado comunitário em saúde mental ${ }^{1-2}$.

Esse processo desencadeou em todo o mundo um movimento conhecido como desinstitucionalização, cujo pressuposto está na busca de manter a pessoa portadora de sofrimento psíquico em contato próximo com sua comunidade e família, tratando-a com dignidade e buscando estimular suas potencialidades ${ }^{1-2}$. Essa lógica é amparada na construção do modelo de reabilitação psicossocial que inclui profundas mudanças no modo de conceber a doença mental e da organização do cuidado e dos serviços de saúde, o que exige uma visão interdisciplinar do trabalho em saúde mental ${ }^{3}$.

Tal modelo requer dos profissionais vinculados à área disposição para rever sua prática, na maioria das vezes cristalizada há anos e influenciada pela lógica da psiquiatria tradicional. Um dos aspectos fundamentais nesse processo é a mudança dessa lógica também na formação e qualificação dos profissionais que deverão atuar baseados em uma nova concepção da doença, da pessoa e da sua família. Isso, em tese, seria o que garantiria a efetivação e resolutividade dos serviços substitutivos como co-responsáveis pelo tratamento, aliada a uma política favorável nas instâncias municipais, estaduais e federais ${ }^{4}$.

Considerando a importância da equipe de enfermagem que sempre esteve envolvida nesse processo e no que diz respeito, especificamente, à questão da formação de profissionais, é foco de nosso interesse, neste estudo, a discussão de aspectos relativos à educação por estarmos à frente do ensino de enfermagem psiquiátrica e saúde mental há mais de vinte anos.

A enfermagem, por sua vez, sempre acompanhou o desenrolar histórico da psiquiatria e sofreu influência desse processo. 0 ensino de Enfermagem Psiquiátrica e Saúde Mental tem se constituído ao longo dos anos um desafio constante para os profissionais da área, tendo em vista a complexidade inerente ao próprio objeto da psiquiatria, da subjetividade do sofrimento psíquico, das políticas de saúde para essa área e das dificuldades de implementação de intervenções que sejam capazes de transformar a práxis no contexto da atenção em saúde mental e psiquiatria ${ }^{5-7}$.

0 estudo de Alencastre ${ }^{8}$ já sinalizava as peculiaridades do ensino nessa área em cada uma das regiões do país e dos movimentos em cada uma delas, no que diz respeito à estruturação das disciplinas e suas características básicas, modelos teóricos, estratégias e sistemas de avaliação e tentativas de articulação dos projetos acadêmicos aos modelos assistenciais inovadores.

A construção de práticas educativas articuladas a modelos substitutivos de atenção psicossocial constitui, na realidade do ensino brasileiro, um desafio constante em todas as regiões do país, especialmente pelas peculiaridades de cada uma delas ${ }^{8}$.

Ao mesmo tempo em que em algumas regiões 0 contexto de ensino prático já esteja articulado a serviços organizados numa nova lógica que permite avanços no estabelecimento de relações entre a equipe de saúde, usuários e comunidade, na compreensão e abordagem da doença mental numa perspectiva de co-responsabilidade social e garantia dos direitos humanos, em outras regiões do Brasil o ensino está imerso num nítido movimento de resistências a mudanças, sedimentado em práticas excludentes ${ }^{8}$.

Assim como em outras regiões do país, em alguns estados da região centro-oeste os avanços no campo da prática em saúde mental são lentos, focados por vezes em experiências isoladas dentro de um contexto maior ainda marcado pela centralização do atendimento nos serviços privados e de caráter hospitalocêntrico. Essa característica interfere, inevitavelmente, no modo como construímos ou desenvolvemos o ensino na área, embora nós, como parte do corpo docente de uma Instituição Federal de Ensino Superior, tenhamos clareza do nosso papel no movimento de resistência aos modelos manicomiais ${ }^{9}$.

Essa situação, por sua vez, nos incitou a buscar estratégias que minimizassem o desconforto de ensinar muito mais sinalizando "o que não fazer" na concepção do trabalho em saúde mental, do que mostrando modelos inovadores e favoráveis ao processo de transformação da assistência psiquiátrica.

Assim, temos como objetivo no presente artigo descrever a experiência dos docentes da área de Saúde Mental e Enfermagem Psiquiátrica da Faculdade de Enfermagem da Universidade Federal de Goiás (FEN/ UFG) no ensino na graduação em enfermagem e o impacto da área na formação do enfermeiro. 
OS DESAFIOS DO ENSINO DE ENFERMAGEM PSIQUIÁTRICA E SAÚDE MENTAL NO ESTADO DE GOIÁS

No Estado de Goiás, contamos com algumas particularidades, permeadas por questões políticas de definição dos rumos da atenção psicossocial que influem diretamente no modo como temos direcionado o ensino e nossa inserção nos processos decisórios extra-universidade.

0 cenário que temos como pano de fundo para 0 ensino, por vezes, é precário e desolador, se pensarmos em experiências de mais êxito em todo o país.

Um estudo realizado ${ }^{9}$, em nível estadual, identificou a existência de 23 instituições de atenção ao indivíduo com sofrimento mental, cujo foco da assistência estava voltado para a internação integral, totalizando aproximadamente 2000 leitos. Desses serviços, em torno de $83 \%$ é representado pelo setor privado e $17 \%$ são serviços disponibilizados pelo setor público, sendo que o único hospital do Estado foi fechado em 1996 e seus pacientes "moradores" foram distribuídos pelos serviços conveniados em todo o Estado.

Do total de leitos em todo o Estado, $85 \%$ deles estão localizados no município de Goiânia, capital do Estado, que integralizava, à época do estudo, 1591 leitos conveniados com o SUS, o que torna Goiás um dos campeões nacionais de hospitais privados do país ${ }^{9}$. Poucas dessas instituições oferecem condiç̃es para o ensino na área, por sinalizarem contradições entre o que acreditamos e consideramos adequadas para a assistência.

0 cenário atual mostra alguns avanços, oriundos da iniciativa da Secretaria Municipal de Saúde de Goiânia - GO em implementar os CAPS (Centro de Atenção Psico-Social), num total de sete, sendo dois para 0 atendimento infantojuvenil (um para álcool e drogas e outro para transtornos mentais) e cinco para adultos (um para álcool e drogas e quatro para transtornos mentais) em um município que tinha cerca de um milhão e duzentos mil habitantes em 2006. Existe ainda um ambulatório especializado, três residências terapêuticas e um pronto socorro que compõe a rede municipal de assistência à saúde mental.

Vale o destaque que em todos esses espaços a inclusão de atividades práticas para o ensino de enfermagem é bastante comprometida, pois esses serviços não contavam com enfermeiros contratados até pouco tempo, além de que com a expansão do número de escolas de enfermagem de nível superior, em torno de 10 só na capital, e as restrições colocadas pelas equipes dessas instituições para um número limitado de alunos é cada vez mais problemática a organização das atividades nos campos de prática.

Nos últimos anos, temos desenvolvido o ensino prático em Enfermagem Psiquiátrica em um serviço considerado mais adequado, de cunho filantrópico, tendo em vista um olhar mais inovador para a atenção em saúde mental, disponibilidade de serviços ambulatoriais e hospital-dia como alternativa ao atendimento e ainda um bom relacionamento com 0 nosso corpo docente e boa aceitação dos alunos.

Além desse espaço, os alunos contam com a permanência reduzida nos CAPS do município em função das questões já relacionadas anteriormente. Essas são limitadas a visitas ou permanência do aluno de três a cinco dias apenas.

Os docentes da FEN/UFG ao longo desses anos estiveram articulados com alguns movimentos que lutam por melhores condições e mudanças no atendimento em saúde mental e também da capacitação de profissionais para atuar na área, participando do Fórum Goiano de Saúde Mental, Projetos de Capacitação de Profissionais da Área, patrocinados pelo Estado, enfim, buscando alternativas para a transformação da situação do atendimento, esperando tornar o ensino também mais voltado para o que dispõe as diretrizes da política nacional de saúde mental e os fundamentos da psiquiatria social ${ }^{1}$.

No entanto, como as deliberações para o avanço dos serviços dependem da esfera política e da atenção que os gestores dão à área, a cada novo mandato municipal e estadual, os profissionais da saúde mental se vêem diante do desafio de, pelo menos, manter os projetos já iniciados e propor avanços, que nem sempre estão no rol de prioridades daquele governo. Esse constitui, na perspectiva de Amarante ${ }^{4}$, um dos obstáculos para a efetivação da desconstrução do aparato manicomial.

Essa situação não reflete apenas a realidade do Estado de Goiás, porém, a falta de uma política regional consolidada na área nos leva ao movimento permanente de avanços e retrocessos no que diz respeito à atenção à Saúde Mental. Esse é na visão dos estudiosos da área um dos grandes desafios da consolidação da reforma psiquiátrica no país ${ }^{1,3-4}$.

\section{A EXPERIÊNCIA DA FACULDADE DE ENFERMAGEM DA UFG}

\section{Para entender os dias atuais: \\ Revendo a história}

A Faculdade de Enfermagem da Universidade Federal de Goiás (FEN/UFG) formou sua primeira turma em 1979, quando, na época, apenas uma disciplina de 90 horas tratava de conteúdos específicos de Enfermagem Psiquiátrica. Até 1996, contava com um único docente responsável por esta disciplina, que mantinha a mesma carga horária e que focava, especificamente, o ensino da clínica psiquiátrica, embora já fosse sinalizado no programa da disciplina a inclusão dos aspectos políticos e sociais da abordagem da doença mental. 
Analisando os programas das disciplinas da FEN/UFG até 1996, observamos que a tendência em manter o ensino focado na assistência clínica reflete o processo histórico de atenção à saúde nessa área, bem como o que era comum ao ensino da enfermagem psiquiátrica na época ${ }^{5,8}$.

Quando da reforma curricular, implementada em 1996, a área passou a contar com três disciplinas ao longo dos cinco anos de curso, perfazendo 240 horas, a saber: Saúde Mental I, Saúde Mental II e Enfermagem Psiquiátrica.

Nessa mesma época, o aumento das disciplinas gerou um fato importante de investimento de docentes na referida área, quando quatro docentes em regime de dedicação exclusiva se vincularam à mesma, embora, desde o início da reforma curricular, nunca foi possível contar integralmente com todos eles, uma vez que três deles estiveram comprometidos com sua formação em nível de pós-graduação.

A perspectiva dos docentes à época era aproveitar o processo de reforma curricular e investir na renovação da lógica da enfermagem psiquiátrica no âmbito da cultura institucional, especialmente por entender a complexidade desse processo e dos esforços que este demanda ${ }^{6-7}$.

Dez anos depois, com a construção do novo projeto político pedagógico do Curso de Graduação da Faculdade de Enfermagem, em atenção às novas diretrizes curriculares do Ministério da Educação, houve a diminuição da carga horária da área em $20 \%$, porém com possibilidade de oferecimento de disciplinas no núcleo livre, o que pode manter ou elevar a carga horária da área de 240 horas.

$\mathrm{Na}$ atualidade, contamos com dois professores doutores especialistas na área, sendo um deles também com formação em Psicologia. Um docente está em fase final de doutoramento na área e outro é mestre. Todos trabalham em regime de tempo integral, sendo que os doutores também atuam no ensino de pós-graduação stricto sensu.

0 quadro 1, na página ao lado, apresenta a composição das disciplinas da área com suas características básicas no currículo vigente da graduação entre 1996 e 2005, já que no momento estamos implementando outro currículo, mas que mantém características semelhantes que serão discutidas a seguir.

Com a reestruturação curricular citada anteriormente e em função da construção do novo projeto político-pedagógico, o conteúdo apresentado no quadro 1 foi desmembrado em três disciplinas que são de responsabilidade dos docentes da área com enfoque no desenvolvimento da pessoa do aluno, da sua capacitação para as relaç̃̃es humanas no contexto do trabalho, do domínio da área específica de clínica psiquiátrica, todos eles voltados também para o contexto do SUS. Vale dizer que o currículo vigente está norteado para o cumprimento do Programa Pró-saúde financiado pelo Ministério da Educação e da Saúde de forma a atender todas as demandas atuais do ensino, em total articulação com a rede de serviços da região.

\section{Focando nossas potencialidades: 0 impacto da área na formação do enfermeiro}

Tendo em vista a situação não muito favorável e a característica da rede de serviços de saúde mental disponíveis no município de Goiânia-GO, os docentes da área têm buscado alternativas para pensar o ensino, de forma a atender a formação do futuro profissional de enfermagem de acordo com os pressupostos da reforma psiquiátrica e, especialmente, visando gerar 0 espírito crítico da assistência dispensada às pessoas em sofrimento psíquico, seja de que natureza for ${ }^{1,3,6-8}$.

Esse movimento partiu de nossa observação de que 0 investimento na formação e desenvolvimento da pessoa do aluno sempre foi uma atribuição da área de saúde mental, porém, sempre de forma marginalizada nos projetos curriculares. Assim, a concepção das três disciplinas que compõem 0 currículo foi feita com base no princípio de que é fundamental oferecer ao aluno oportunidade para entender as relações interpessoais no contexto do trabalho em saúde, de modo geral, partindo do autoconhecimento e autopercepção dos limites e potencialidades de cada um ${ }^{10-11}$.

Essa iniciativa teve boa aceitação no contexto institucional, o que deu a área de saúde mental/ enfermagem psiquiátrica maior visibilidade, projetandoa para além da tarefa de ensinar o relacionamento terapêutico e as especificidades inerentes à clinica psiquiátrica. Assim, a área assumiu a importante tarefa também de formar a pessoa do aluno para o contexto do trabalho em saúde, integrando as dimensões assistenciais e gerenciais.

As demandas do ensino no Curso de Graduação em Enfermagem da FEN/UFG, focadas na busca de uma formação integral do enfermeiro, foram acrescidas de um clima favorável, em particular, para a integração das disciplinas da área com outras disciplinas das séries onde elas se encontram. Assim, as disciplinas da área foram se adequando às necessidades de atender a formação geral do profissional enfermeiro no desenvolvimento das suas competências interpessoais, relacionais e de gestão, pensando especificamente na importância do fortalecimento da pessoa do profissional, além de estarem voltadas para a capacitação e fortalecimento do enfermeiro para compreender e planejar ações de humanização do atendimento em saúde ${ }^{10-11}$, com destaque especial ao cuidado do cuidador. 
Quadro 1:

Disciplinas da área de Saúde Mental/ Enfermagem Psiquiátrica do currículo vigente de 1996 a 2005 da FEN/UFG.

Goiânia/GO, 2006.

\begin{tabular}{|c|c|c|c|}
\hline 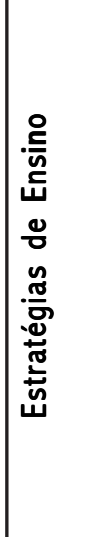 & 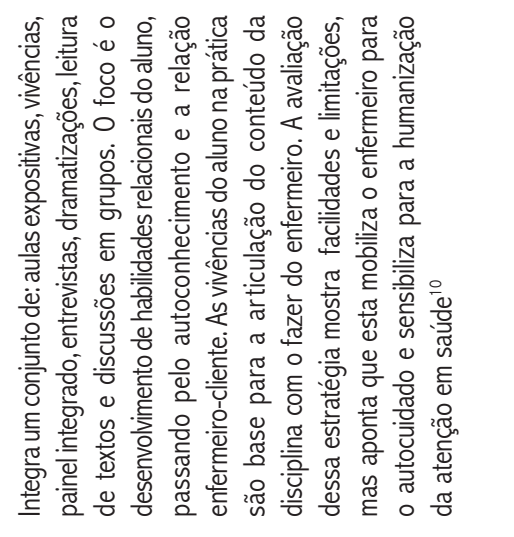 & 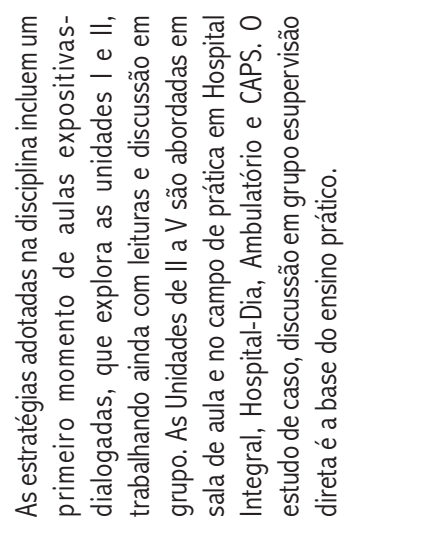 & 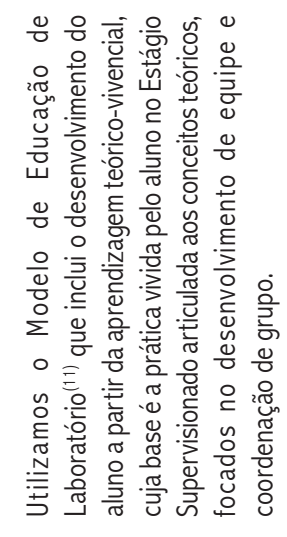 \\
\hline 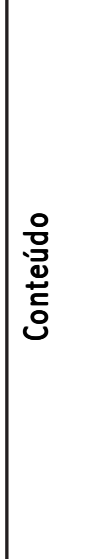 & 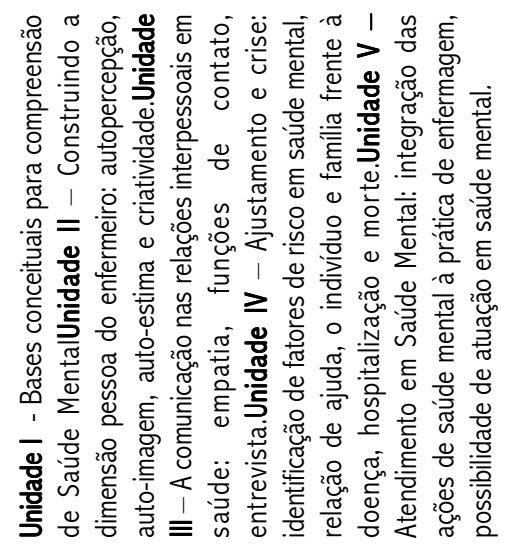 & 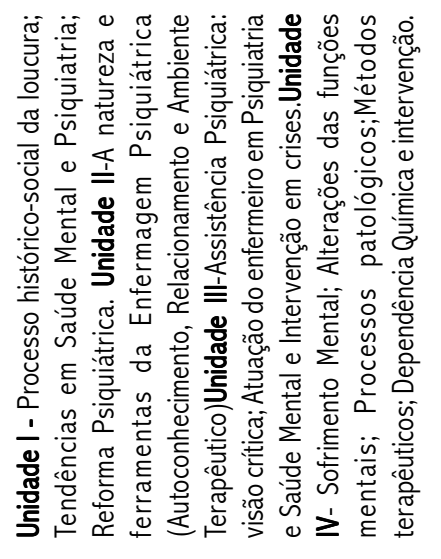 & 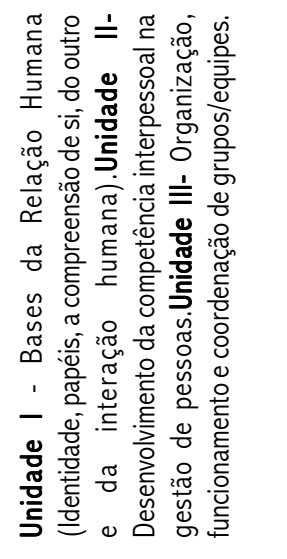 \\
\hline & 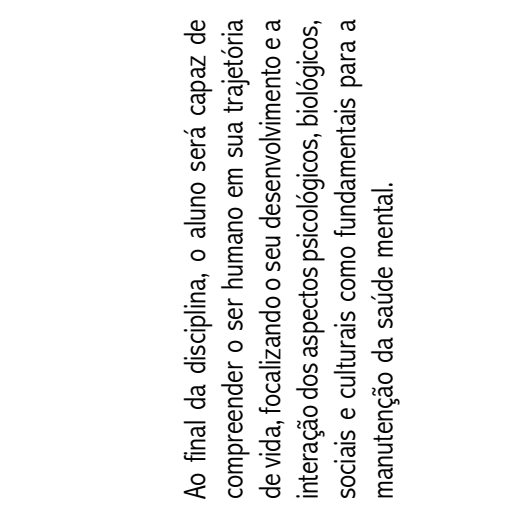 & 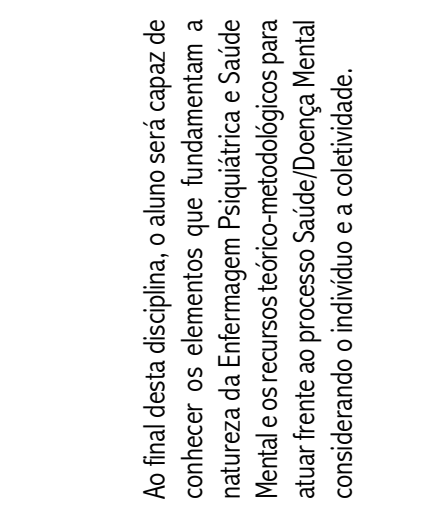 & 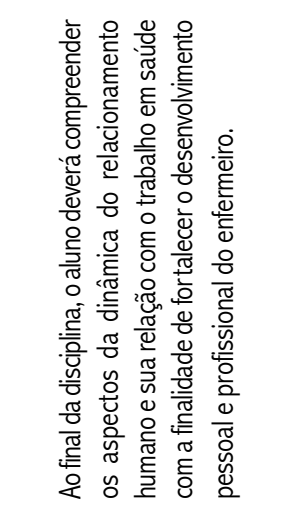 \\
\hline 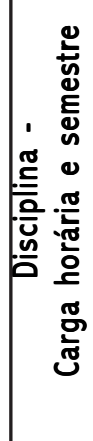 & 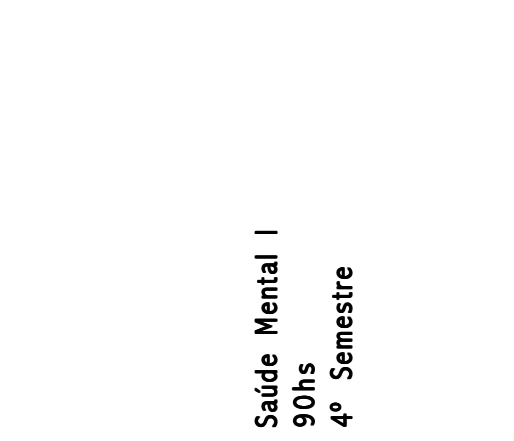 & 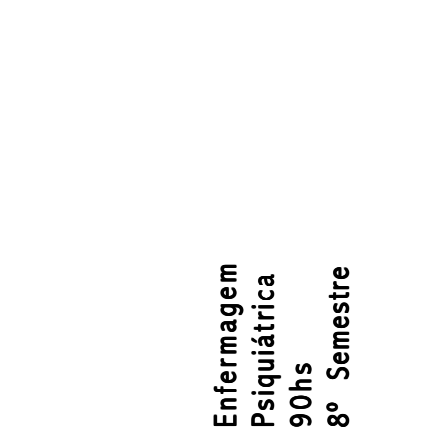 & 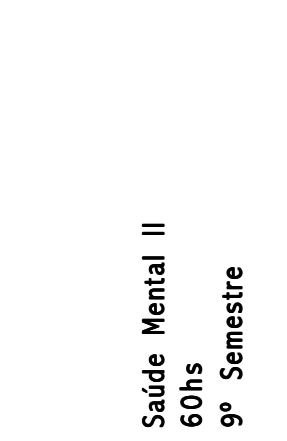 \\
\hline
\end{tabular}


A peculiaridade da experiência da área de Saúde Mental/Enfermagem Psiquiátrica da FEN/UFG é marcada então pela mobilização do corpo docente para uma mudança de postura e concepção da área no processo de formação do enfermeiro. Isso quer dizer que a partir da implantação do currículo de 1996, essa passou a influenciar a formação do enfermeiro como um todo e não se ocupar apenas do conteúdo de clínica psiquiátrica como acontecia até então.

Esse processo foi influenciado pelas inquietações dos docentes e sua motivação para mudar a perspectiva do ensino de graduação, que passou a ser mais focado no desenvolvimento de habilidades relacionais do enfermeiro, não apenas na atenção em psiquiatria, mas como pressuposto da postura profissional, de modo que esta permeasse as atitudes do aluno durante os cinco anos de estudo. Também foi fundamental o investimento dos docentes da área no seu processo de qualificação, uma vez que inicialmente apenas um docente possuía o titulo de doutor.

0 investimento nesse sentido levou ao desenvolvimento de dois estudos ${ }^{10,12}$ em nível de pósgraduação - mestrado e doutorado - que se tornaram a base para o processo de reconstrução do projeto político-pedagógico da FEN/UFG. 0 primeiro ${ }^{10}$ se ocupou da percepção do aluno sobre sua formação, o que trouxe subsídios para o corpo docente repensar sua postura nas relações que estabelece com 0 aluno e os reflexos dessa na construção do profissional que fosse sensível a atender o cliente de forma integral. E o outro $^{12}$, por se constituir numa pesquisa-ação, auxiliou o corpo docente durante o período de discussão da construção do projeto político-pedagógico, especificamente na discussão dos princípios filosóficos que o embasariam até a revisão minuciosa de conteúdos, tendo em vista as diretrizes curriculares e o eixo condutor da perspectiva ética humanista da formação do enfermeiro.

Assim, os docentes da área tiveram uma participação política importante e estratégica na defesa, não apenas dos pressupostos filosóficos da ética-humanista, mas da garantia de sua inclusão no conteúdo do projeto e nas ações que o tornaria vivo. Esse movimento mostra que os esforços para a construção de políticas institucionais, quer sejam na educação ou na saúde, só transformam a realidade quando construídas no coletivo e concebidas por meio da discussão onde as diferenças são ponderadas e negociadas ${ }^{3,4}$.

Obviamente, esse processo não foi sempre harmônico, havendo momentos de intensas resistências, que foram contornadas com o desejo coletivo de algumas mudanças efetivas de postura profissional, bem como da responsabilidade de formar profissionais capazes de transformar a realidade e atender aos princípios das políticas de saúde ${ }^{12}$.

Consideramos pertinente ressaltar o processo de integração da área da Saúde Mental/Enfermagem Psiquiátrica com as demais áreas do curso, principalmente com as de enfoque eminentemente clínico, que passaram a reconhecer e valorizar a comunicação terapêutica como tecnologia de cuidado, tal como as define Tavares e colaboradores ${ }^{13}$.

Já no início, na $1^{\text {a }}$ série do curso, há uma estreita relação entre as docentes das disciplinas que fundamentam a assistência de enfermagem e as docentes da disciplina Saúde Mental I, cuja preocupação primeira é 0 acolhimento do aluno no universo acadêmico, geralmente bastante distinto das suas experiências anteriores. Este chega imerso de expectativas, dúvidas e receios diante do novo caminho que tem a percorrer.

Nesta ocasião, algumas aulas são programadas objetivando conhecer o aluno ingressante, além de, prioritariamente, favorecer o seu autoconhecimento num período especial da sua trajetória de vida. Por meio de atividades vivenciais e/ou lúdicas, temos observado a efetividade deste espaço pedagógico que tem promovido maior integração professor-aluno e facilitado a percepção de si próprio perante suas inquietações relativas a este momento existencial, expressas pela maioria dos alunos. Isso contribui para o sentimento de pertença tão importante para 0 desenvolvimento saudável do ser humano.

Ao longo desse mesmo semestre, outros encontros com a área são planejados para aprofundar tais questões como para discutir as experiências dos alunos nos campos de prática, procurando refletir como eles se percebem como cuidadores, suas potencialidades e dificuldades, particularmente voltando para o desenvolvimento de suas competências e habilidades interpessoais. Embora essas sejam experiências comuns em alguns outros estados do país, em Goiás, ela se constitui na única experiência, haja vista que temos auxiliado colegas de outros cursos que se preocupam em buscar alternativas para um ensino mais efetivo na área.

$\mathrm{Na}$ seqüência da grade curricular quando os alunos, além da assistência na comunidade, adentram o ambiente hospitalar, mais uma vez há uma integração da Saúde Mental com as disciplinas que lidam com técnicas básicas de enfermagem, cuidados assistenciais aos portadores de diversas patologias crônicas e/ou graves. Nessas ocasiões, é comum o contato com experiências inéditas de cuidados com pessoas em situações de risco, na qual geralmente sentem-se 
despreparados e sem o suporte emocional adequado para o enfrentamento. Esse momento pode constituir uma situação de crise para o aluno, e a área é a referência para sua abordagem.

Dessa maneira e com o intuito de amenizar o desconforto dos alunos e melhor prepará-los para a assistência humanizada, partimos do princípio de que é fundamental alicerçar o futuro profissional nos aspectos ético-humanistas, fortalecendo ele próprio de modo a ser também agente da construção da sua formação pessoal e acadêmica ${ }^{11,14}$.

0 aprendizado da prática da interdisciplinaridade ${ }^{3}$, por outro lado, tem sido um desafio, haja vista que, acostumados com o formato tradicional curricular, é muito difícil o exercício de ceder, compreender a visão e perspectiva do outro, bem como entender a lógica do trabalho construído coletivamente. Nesse contexto, o aprendizado das relações interpessoais, objeto de nosso trabalho, precisa também ser vivenciado na prática e fazer eco a teoria que defendemos junto aos alunos e colegas.

No entanto, buscar essa unidade é uma grande aventura, pois nos coloca, alunos e docentes, diante do desafio de quebrar paradigmas há anos consolidados e cristalizados na lógica do pensar e fazer em saúde ${ }^{4}$. Ser coerente, nesse sentido constitui uma meta para fazer valer o que os alunos chamaram nossa atenção ao apontarem em um estudo ${ }^{10}$ que muitas vezes no processo de ensino o holismo ocorre só na teoria.

Isso nos remete ainda à dificuldade da construção de uma nova lógica de atenção em saúde mental, quando técnicos e usuários devem discutir juntos os caminhos para a construção do modelo adequado às necessidades e às expectativas ${ }^{4,6}$. Esse exercício, em geral, nos coloca diante de nossas contradições e receios de mudanças e do novo, aspecto já discutido por outros estudos ${ }^{6-8}$.

Talvez o que seja mais evidente e concreto desse aprendizado é o resultado que esse investimento tem trazido na nossa prática, quando deixamos de ser um grupo marginalizado por estudar e se ocupar do subjetivo, para nos mostrar com disposição para a troca, o exercício da criatividade e inovação, principalmente por adotarmos estratégias de ensino pouco tradicionais e mais integradoras ${ }^{11-14}$.

Os alunos também têm mostrado que nossos investimentos têm dado resultados concretos no seu desempenho ${ }^{11-14-15}$. A disciplina Saúde Mental II, oferecida na última série do curso ao utilizar a Educação de Laboratório como metodologia de ensinoaprendizagem, tem mostrado resultados bastante positivos, na medida em que privilegia a experimentação, em sala de aula, de possíveis situações vivenciadas pelo enfermeiro com a devida teorização dos aspectos pertinentes ao desenvolvimento das competências relativas ao papel gerencial que assume no exercício profissional. Uma pesquisa realizada recentemente ${ }^{15}$ mostrou 0 impacto dessa metodologia na formação do enfermeiro e, especificamente, no modo como 0 aluno enfrenta os desafios de se colocar nesse papel.

Consideramos esse o ponto forte da disciplina, pois é nesse contexto que se dá a conscientização da importância do papel de gestor e líder da equipe de enfermagem e de saúde. Esse processo é bastante complexo, e é para o aluno uma árdua tarefa de se ver diante do espelho e da necessidade de assumir as atribuições da sua profissão. Os contatos com os limites, potencialidades e com a realidade do final do curso geram muito estresse, exigindo uma atenção do docente para canalizar o potencial terapêutico do grupo em beneficio de todos. Geralmente essa é uma disciplina que começa com alguns alunos faltando ou dando pouca importância a ela, mas que ao final do ano tem como resultado a sala lotada e um interesse genuíno do grupo em estar presente ${ }^{14}$.

0 impacto disso também pode ser visto pelo interesse de docentes de outras áreas em se aproximar das metodologias utilizadas pela área, procurando rever o seu padrão de funcionamento, especialmente a relação professor-aluno, diante da sua importância no processo de humanização da assistência. Os trabalhos desenvolvidos pelos docentes e discussões durante as reuniões de reestruturação do projeto político-pedagógico motivou a revisão dos conceitos dos princípios ético-humanistas, fortemente refletido na área, de modo a torná-los não só um discurso no currículo escrito, mas uma ação na prática docente ${ }^{12}$.

Outro aspecto a ser destacado como potencialidade da área é a abertura e parceria conseguida na instituição onde desenvolvemos a prática de Enfermagem Psiquiátrica, que tem aberto oportunidades aos alunos interessados para estágios voluntários. Inclusive, com a mudança curricular e 0 aumento da carga horária do Estágio Supervisionado, o referido campo passou a ser incluído como campo de prática para os alunos da quinta série. Além disso, por iniciativa da instituição, discutimos a possibilidade de oferecermos assessoria para a organização de um grupo de pesquisa que integre os profissionais locais, alunos e docentes da FEN/UFG.

$\mathrm{Na}$ composição do atual projeto político-pedagógico do curso da FEN/UFG, houve alteração no nome, alocação, carga horária das disciplinas da área, embora a essência da proposta da interdisciplinaridade tenha se mantido, com grandes possibilidades da inserção do seu corpo de conhecimentos em outros momentos 
focais em disciplinas que abordam questões ligadas à existência humana e suas necessidades, situação que ora se encontra em fase de aproximação e amadurecimento.

Atualmente, a FEN/UFG está fortalecendo sua parceria com o Hospital das Clínicas/UFG, com a participação direta de alguns de seus docentes num grande projeto de pesquisa e extensão voltado para a educação permanente para os trabalhadores de enfermagem. Esse tem possibilitando trocas de experiências nos cursos e oficinas em que há um maior contato com enfermeiros do serviço, que geralmente participam da supervisão de nossos alunos. Esse processo, por conseqüência, tem diminuído distâncias que por vezes dificultam as relações entre os alunos e os profissionais da prática.

Nessa empreitada, os docentes da área da Saúde Mental estão envolvidos nesse processo que tem se mostrado desafiador e estimulante de mudanças desejadas entre as partes.

\section{Revendo nossas fragilidades: Buscando novos avanços}

Embora seja contraditório, o campo da prática para as aulas práticas da Enfermagem Psiquiátrica é ainda o nosso maior desafio, por ser restrita, na sua maior parte, a uma única instituição. Embora tenhamos atualmente um bom relacionamento com a instituição onde ela ocorre, como abordado anteriormente, essa é restrita. Por falta de tempo de investimento dos docentes no estabelecimento de parcerias mais efetivas com os serviços, muitas vezes nossa permanência é temporária e descontínua.

Procurando vencer os desafios da assistência norteada para os princípios do SUS e atendendo as atuais diretrizes da atenção psiquiátrica, temos tentado, em todas as iniciativas de parceria com as disciplinas, inserir os alunos da graduação em atividades que incorporem ações de saúde mental em qualquer serviço de saúde. Acreditamos também que, com o retorno de um docente afastado para doutoramento, tenhamos mais condições de elaborar projetos que permitam a articulação entre as atividades de ensino, extensão e pesquisa.

Por outro lado, a opção pelo uso de metodologias participativas e menos tradicionais de ensino tem gerado desgastes relacionados às resistências e dificuldades dos alunos frente ao desafio do autoconhecimento, auto-aceitação, descoberta de limitações, relacionamento interpessoal. Para contornar essas situações, temos investido no desenvolvimento do docente para ser continente a situação do aluno, para conseguir estimulá-lo a participar e a trilhar esse caminho, que para alguns é bastante incômodo ${ }^{11}$.

Ainda, é também um grande desafio manter o modelo de educação de laboratório como opção metodológica, por ser um processo muito desgastante para o docente, pois essa exige permanentemente disponibilidade para lidar com o novo a cada encontro. Nada é fixo ou predeterminado, mas definido conforme a necessidade e disponibilidade das pessoas para com a tarefa, inclusive quando as resistências são maiores que a disposição. Para tanto, a supervisão do docente é ferramenta que garante a sobrevivência da disciplina e a saúde do docente.

0 exercício de pensar nas fragilidades e limitações do nosso processo de ensinar Saúde Mental/ Enfermagem Psiquiátrica nos remete também a uma análise do movimento dos docentes da área nos últimos doze anos na FEN/UFG. Esse só foi possível, pois houve uma disposição para a convivência de idéias, princípios, diferentes pontos de vistas, o que também não é um processo fácil, mas que tem possibilitado o nosso crescimento coletivo como área, bem como o pessoal.

\section{CONSIDERAÇÕES FINAIS}

Pensar o ensino de Enfermagem Psiquiátrica e Saúde Mental no processo de formação do enfermeiro na nossa realidade é fundamental para percebermos os avanços e recuos que temos vivenciado ao longo dos anos e os dilemas que encontramos, na condução das disciplinas no contexto de mudanças da estrutura curricular.

Embora a rede de atenção psicossocial no Estado de Goiás seja extremamente fragilizada e ineficiente, cerceada por interesses dos mais variados e limitada pela falta de uma política que favoreça a construção de modelos mais adequados às necessidades dos usuários, familiares e da sociedade como um todo, encontramos nessa situação de aparente caos, motivos para buscarmos formas de utilizar a carga horária destinada à área de Saúde Mental/Enfermagem Psiquiátrica de forma criativa e inovadora, razão pela qual nos permite afirmar que nossa experiência seja singular no contexto do ensino nessa área.

Nossa trajetória tem sido marcada por muitos desafios de marcar o lugar da área no contexto do ensino de enfermagem na primeira fila. A Enfermagem Psiquiátrica e de Saúde Mental que, por muito tempo, foi considerada reduto de docentes excêntricos, "diferentes", parece ter tomado uma outra posição na hierarquia de valores na formação do enfermeiro, pelo menos na nossa realidade.

Possivelmente o foco que utilizamos para compreender o sujeito como um todo, com seus 
desejos, limites, potencialidades e valores, nos permitiu trilhar caminhos na busca por soluções criativas e transformadoras nas relações humanas, aspecto tão valorizado no mundo atual.

Esse investimento nos permite observar que a área de saúde mental / enfermagem psiquiátrica contribui para a formação do enfermeiro em três direções. Primeiramente, ao oferecer oportunidade ao aluno de ser apresentado a ele mesmo, com condições para descobrir suas melhores qualidades humanas, mas também seus temores e imperfeições onde pode lapidar-se durante os cinco anos em que se dedica ao processo de construção do ser profissional. Evidentemente que esse não é um processo linear, alguns aproveitam melhor essa chance do que outros, mas, indubitavelmente, essa experiência deixa marcas e memórias que poderão ser acessadas a qualquer momento da vida da pessoa.

Em segundo lugar, esta área possibilita que o aluno se perceba com os outros na dinâmica da vida coletiva, entendendo suas relações com os colegas de turma, inicialmente e depois, com os docentes, com os pacientes e profissionais dos serviços onde ele atua.

Assim, acreditamos que, mesmo não dispondo de condições adequadas e politicamente corretas no que diz respeito à atenção psicossocial e de dispositivos para uma assistência mais digna ao sujeito que sofre mentalmente e sua família, ao darmos condições para que o enfermeiro possa se fortalecer como pessoa, certamente estamos munindo os futuros profissionais de ferramentas para o enfrentamento das relações humanas em qualquer local em que venham trabalhar.

A terceira vertente em que temos atuado na formação do enfermeiro é na sua formação como gestor e coordenador de grupos e equipes. Esse

\section{Referências}

1. Amarante $P$, organizador. Psiquiatria social e reforma psiquiátrica. Rio de Janeiro (RJ): Ed. da FIOCRUZ; 1994.

2. Desviat M. A reforma psiquiátrica. Rio de Janeiro (RJ): Ed. da FIOCRUZ; 1999.

3. Braga VA, Souza AMA, Fraga MNO. Políticas de saúde, saúde mental e interdisciplinaridade: avaliação e métodos. Fortaleza (CE): PósGraduação DENF/UFC/FFOE/ FCPC; 2002.

4. Amarante P. 0 planejamento na desconstrução do aparato manicomial. In: Gallo E, organizador. Planejamento criativo: novos desafios técnicos em políticas de saúde. Rio de Janeiro (RJ): Relumé-Dumará; 1992.

5. Rocha RM. Enfermagem psiquiátrica: que papel é este? Rio de Janeiro (RJ): Instituto Franco Basaglia/Ed. Te Corá; 1994. movimento da área tem sido responsável por um diferencial na formação do profissional formado pela FEN/UFG. Essa afirmação tem como base o retorno que os serviços nos tem dado, sinalizando a importância de proporcionarmos aos alunos a oportunidade em exercitar esse papel ainda na universidade.

Nesse sentido, as adversidades provocadas por condições externas e as limitações da Universidade acabaram nos impulsionando para a busca de alternativas para alocar de forma integrada o conhecimento que é próprio da área, o que no nosso entendimento acabou se tornando um privilégio para nós docentes e alunos.

Em meio a esse panorama temos consciência das limitações da nossa experiência, assim como reconhecemos que grande parte do sucesso dela se dá em função da continência do grupo docente da FEN/ UFG como um todo, da liberdade para criar concedida pela instituição e do espírito inquieto e curioso dos docentes da área.

Finalizamos essa reflexão nos remetendo à idéia de que não é possível resolvermos nossos impasses, dilemas e dificuldades no campo da saúde mental e frente à responsabilidade de ensinarmos saúde mental/ enfermagem psiquiátrica com os mesmos pressupostos e idéias que ontem tivemos. É fundamental um olhar para os desafios e soluções do futuro, sem receio do novo, inusitado.

É fundamental, nesse contexto, manter o foco nos princípios humanistas que envolvem nossa formação, o senso de responsabilidade social e a crença no potencial do ser humano, pois as soluções para os problemas encontrados na prática assistencial em saúde mental e no ensino desse conhecimento estarão sempre além do óbvio e do que parece muito comum, mas aliados à nossa capacidade de acreditar e sonhar o impossível.

6. Olschowsky A, Barros S. Graduaçäo em enfermagem: aprendendo a aprender a reforma psiquiátrica brasileira. Rev Esc Enferm USP 1999 dez; 33(4): 377-83.

7. Miranda CML, Rocha RM, Sobral VRS. 0 ensino, a pesquisa e a assistência de Enfermagem psiquiátrica. Rev Enferm UERJ 1999 juldez; 7(2): 193-97.

8. Alencastre MB, organizador. Estudos sobre ensino de enfermagem psiquiátrica e saúde mental no Brasil. ljui(RS): Unijui; 2000.

9. Munari DB, Medeiros M. Assistência psiquiátrica em Goiás: realidade e desafios Programa.do $51^{\circ}$ Congresso Brasileiro de Enfermagem. 10] Congreso Panamericano de Enfermeria; 1999 out. 2-7; Florianópolis.(SC), Brasil. Florianópolis.(SC): ABEn; 2000.

10. Esperidião E, Munari DB. Holismo só na teoria: a trama dos sentimentos do graduando de enfermagem. Rev Esc Enferm USP 2004 set-dez; 38 (3): 332-40. 


\section{Sobre as Autoras}

estratégias didáticas facilitadoras para o auto conhecimento do enfermeiro. Rev Latino-Am Enferm 2002 jul; 10(4): 516-22.

12. Esperidião E. Repensando a formação do enfermeiro: o processo de conscientização crítica e práticas docentes à luz do referencial ético-humanista. [tese de doutorado]. Ribeirão Preto (SP): Escola de Enfermagem de Ribeirão Preto/ USP; 2005.

13. Tavares CMM, Branchat MA, Conceição S, Silva B, Knust R. Therapeutical activites as technologies of caring in mental health. [online] Brasilian Journal of Nursing. 2002 Aug. [citado 12 Sep 2006] 1 (2) Disponível em: www.uff.br/nepae/objn102tavaresetal.htm.

14. Munari DB, Merjane TVB, Cruz RMM. A aplicação do modelo de educação de laboratório no processo de formação do enfermeiro. Rev Enferm UERJ 2005 set-dez; 13 (3): 263-69.

15. Munari DB, Oliveira NF, Fernandes CNS. 0 modelo de educação de laboratório na formação do enfermeiro: avaliação do graduando de enfermagem. Rev Enferm UERJ 2006 set/dez; 14 (3): 385-90.

\section{Denize Bouttelet Munari}

Enfermeira. Profa. Dra. Titular da Faculdade de Enfermagem da UFG. Membro Titular da Sociedade de Psicoterapia, Psicodrama e Dinâmica de Grupo/SOBRAP/GOIAS.

\section{Maria Tereza Hagen Godoy}

Mestre em Enfermagem. Professora assistente da Faculdade de Enfermagem/Universidade Federal de Goiás - Goiânia-GO

\section{Elizabeth Esperidião}

Enfermeira e Psicóloga. Doutora em Enfermagem. Professora Adjunto da Faculdade de Enfermagem/Universidade Federal de Goiás. 